\title{
On Nonlinear Deformation of Concrete at Elevated Temperatures
}

\author{
Lyudmila S. Polyakova ${ }^{1, a^{*}}$,Vladimir I. Andreev ${ }^{2, b *}$
}

${ }^{1,2}$ NR Moscow State University of Civil Engineering, Yaroslavskoye sh., 26, 129337 Moscow, Russia

\author{
al.poliakova@inbox.ru, ${ }^{\text {basv@mgsu.ru }}$
}

\begin{abstract}
Keywords:nonlinearity, inhomogeneity, concrete, elevated temperature
Abstract.The paper considers the influence of elevated temperatures in the range from $20{ }^{\circ} \mathrm{C}$ to $200{ }^{\circ} \mathrm{C}$ in the mechanical properties of the concrete: the thermal expansion, elastic modulus, shear deformation coefficient, strength.Functions describing the dependences of the mechanical characteristics of concrete on temperature as well as functions approximating the nonlinear diagram deformation of concrete at elevated temperatures are proposed.
\end{abstract}

\section{Introduction}

Under normal operating conditions, concrete and reinforced concrete structures are often exposed to non-force effects that cause changes in their deformed state. The effect of temperature significantly changes the nature of the work of the structure. Under the influence of elevated and negative temperatures in the construction there is an inhomogeneity of concrete, caused by a change in its properties.

The problem of calculating reinforced concrete structures with temperature is to develop methods that take into account the physical nonlinearity of the deformation under conditions of substantial inhomogeneity and anisotropy of the material, as well as the development of temperature-shrinkage and elastic deformations of concrete.

The article describes the influence of elevated temperatures on the mechanical properties of the concrete. We consider the temperature range from $20^{\circ} \mathrm{C}$ to $200^{\circ} \mathrm{C}$, as it covers a wide area of the operating modes of reinforced concrete structures. At higher temperatures, special heat-resistant concretes are used which are not considered here, although the presented dependences can be extended to these concretes.

The effect of elevated temperatures on concrete causes temperature deformation, changes in deformation characteristics (Young's modulus, Poisson's ratio) and strength properties of the material, affects the overall diagram of concrete deformation.

\section{Forced deformations from the temperature effect}

In the absence of power loads, the effect of temperature on concrete leads to the occurrence of temperature deformations in it and to the further development of shrinkage deformations. The total value of deformations of unloaded concrete under the influence of elevated temperatures includes three types of deformation - shrinkage deformations, reversible and irreversible temperature deformations.Accordingly, the temperature-shrinkage deformations of concrete can be determined by the formula:

$$
\varepsilon_{T}=\varepsilon_{T}^{i r}(T)+\varepsilon_{T}^{r}(T)-\varepsilon_{s h r}(T)
$$

Irreversible temperature deformations are determined by the formula:

$$
\varepsilon_{T}^{i r}(T)=\alpha^{i r}(T) \Delta T
$$

where $\alpha^{i r}(T)$-coefficient of linear irreversible temperature deformations; $\Delta T=T-T_{0}$, and $T_{0}=20^{\circ}$ -the value of the normal temperature. 
In general, the value of the coefficient $\alpha^{i r}$ depends on the temperature, the heating rate and the humidity of the concrete at the beginning of the heating. However, for concrete which has humidity close to equilibrium at normal temperature, the coefficient $\alpha^{i r}$ depends only on the temperature (Fig. 1) and is approximated by the expression:

$$
\alpha^{i r}(T)=1,35 \cdot 10^{-5} \cdot \exp (-0,027 \Delta T) .
$$

It is assumed in the calculations that irreversible temperature deformations develop completely during the first short-term heating, with the exception of heating temperatures up to $90^{\circ} \mathrm{C}$. For this range, it is conventionally assumed that during the first heating $50 \%$ of irreversible deformations develop, the rest during the next 40 hours of isothermal tests [1].

Reversible temperature deformations are characterized by the coefficient of linear reversible temperature deformations and are determined by the formula:

$$
\varepsilon_{T}^{r}(T)=\alpha^{r}(T) \Delta T \text {. }
$$

The coefficient of reversible linear temperature deformation of concrete having moisture equilibrium with the medium depends only on the temperature (Fig. 2) and is approximated by the expression:

$$
\alpha^{r}(T)=0,76 \cdot 10^{-5}+7,5 \cdot 10^{-8} \cdot \exp (0,02 \Delta T) .
$$

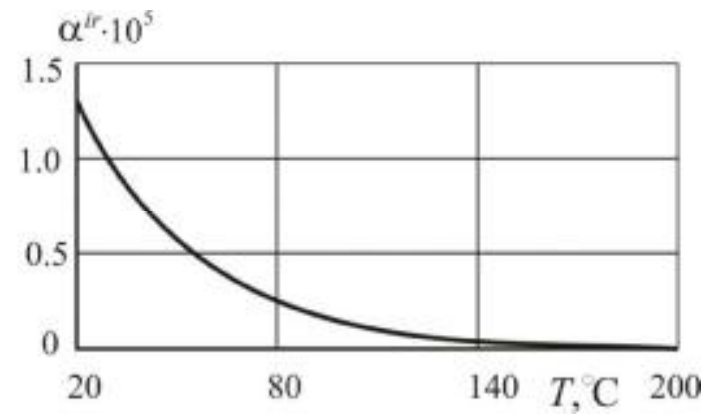

Fig. 1. Coefficient of linear irreversible temperature deformations

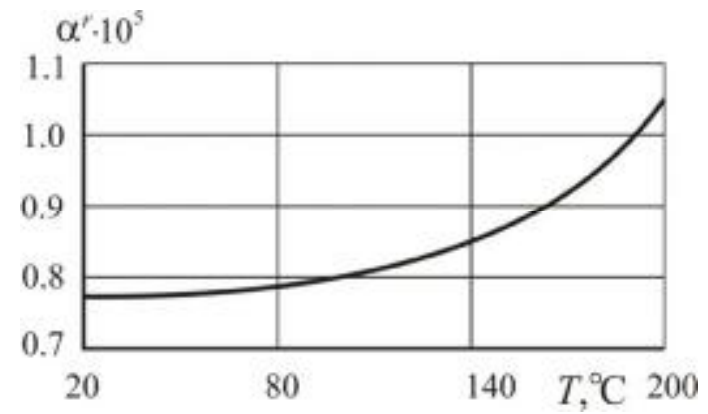

Fig. 2. Coefficient of linear reversible temperature deformations

Shrinkage deformations of concrete are determined by the formula:

$$
\varepsilon_{\text {shr }}=-\beta \Delta U \text {, }
$$

where $\beta$-coefficient of linear shrinkage; $\Delta U=U-U_{0}$ - change in humidity of concrete.

Over the entire range of elevated temperatures, the relationship between the coefficient of linear shrinkage, temperature and humidity of concrete can be satisfactorily approximated by formula [2]:

$$
\beta(T, U)=\beta_{0}-1,37 \cdot 10^{4} \cdot \Delta T+5,6 \cdot 10^{-2} \exp \left(-2,5 \cdot 10^{3} \cdot \frac{U}{\Delta T}\right),
$$

Where $\beta_{0}$ is the coefficient of linear shrinkage at normal temperature (for heavy concrete is adopted $3 \cdot 10^{-2}$ ); $U$ - humidity of concrete at elevated temperature $T$.

Thus formula (6) for elevated temperatures takes the form:

$$
\varepsilon_{\text {shr }}=-\beta(T, U) \Delta U \text {. }
$$

For reliable determination of shrinkage deformations of concrete under the influence of elevated temperatures, it is necessary to have sufficiently accurate initial information on the distribution of humidity in the concrete of the design to be calculated at normal and elevated temperatures.If this information is not available, we can use a simplified technique for the calculation of shrinkage 
deformations.In this case, in the formula (8), the parameters that are functions of changing the humidity of concrete are replaced by new parameters that are functions of the time of action of the temperature. Thetechniqueisdescribedindetailin [3].

\section{Modulus of elasticity}

The modulus of elasticity of heavy concrete depends mainly on the heating temperature and is practically independent of the duration of its action. At the first short-term heating there is a sharp decrease in the modulus of elasticity, which, depending on the temperature, is $20-42 \%$. A prolonged isothermal effect of temperature does not cause a further change in the modulus of elasticity. The change in the initial modulus of elasticity of concrete at elevated temperatures is shown in Fig. 3 and is described by the relationship:

$$
E(T)=E_{0} \cdot\left(T_{0} / T\right)^{0,24},
$$

where $E_{0}-$ modulus of elasticity at normal temperature $T_{0}=20^{\circ} \mathrm{C}$.

\section{Poisson ratio}

The Poisson's ratio of concrete is practically independent of temperature and significantly reduced only at temperatures close to $200^{\circ} \mathrm{C}$ (Fig. 4). This dependence can be described by the formula:

$$
v(T)=\mathrm{v}_{0}-2,6 \cdot 10^{-4} \cdot\left(T_{0} / T\right)^{-2,5},
$$

Where $v_{0}=0,24-$ Poisson's ratioat normal temperature $T_{0}=20^{\circ} \mathrm{C}$.

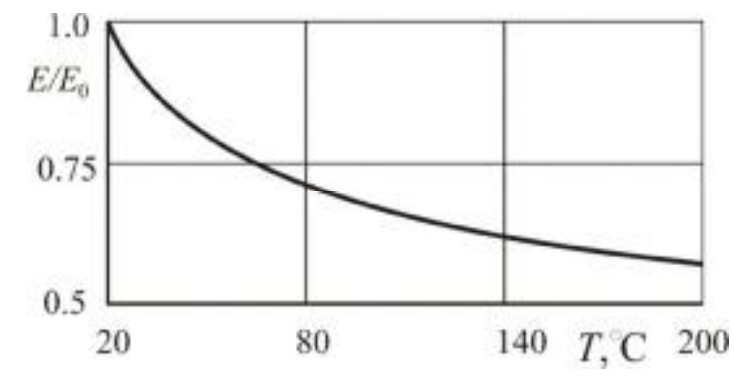

Fig. 3. Changing the concrete elastic modulus

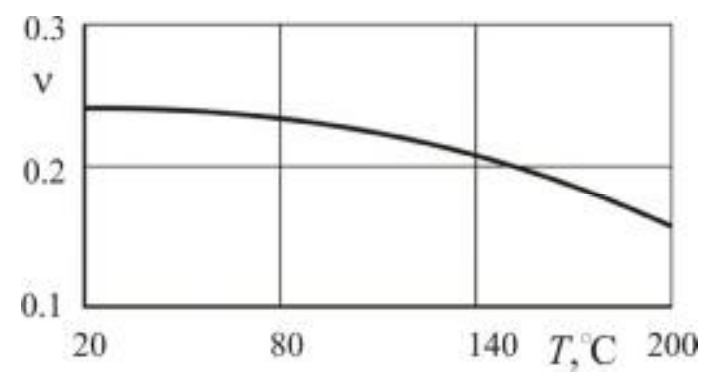

Fig. 4. Changing the Poisson's ratio

\section{Concrete deformation diagram}

The strength of heavy concrete for axial compression at elevated temperatures depends on the heating temperature, the duration of its action and the test regime. The greatest decrease in strength is noted at the first short-term heating. The prolonged isothermal action of the elevated temperature in comparison with short-term heating leads to an increase in the strength of the concrete. Cooling to normal temperature after short-term heating and prolonged isothermal soaking does not cause a further change in the strength of concrete [4].

To build a technique for calculating the stress-strain state of reinforced concrete structures with allowance for temperature effects, it is necessary to have analytical dependencies describing the complete diagram of concrete deformation at elevated temperatures.Diagram $\sigma-\varepsilon$ determined from the uniaxial compression tests, but in the general case, for a description volumetric state of stress is used a diagram relating the intensity of the stresses and strains.

To convert the experimental data of concrete deformation under compression under conditions of elevated temperatures in the regime of prolonged heating, given in [2], the following formulas were used: 


$$
\sigma_{i}=\sigma, \varepsilon_{i}=\varepsilon-\frac{1-2 v_{0}}{3 E_{0}} \sigma
$$

To approximate the non-linear stress-strain diagram useful relationship with the three constants [5]:

$$
\sigma_{i}=E \varepsilon_{i}-A \varepsilon_{i}^{\alpha},
$$

where $E$-initialelasticitymodulus, $A$-a constant with the dimension of stresses, $\alpha$ - the exponent (dimensionless). This dependence allows one to closely approximate the experimental data and, in addition, at $\varepsilon_{i} \rightarrow 0$ is automatically transferred to the Hooke's law for linear-elastic material.

The inhomogeneity of concrete resulting from the effect of elevated temperatures is taken into account by replacing the constants $E, A$, and $\alpha$ by the functions $E(T), A(T)$ and $\alpha(T)$ [6]. The resulting deformation diagrams are well approximated by the functions[7]:

$$
E(T)=E_{0}\left(T_{0} / T\right)^{k_{E}}, A(T)=A_{0}\left(T_{0} / T\right)^{k_{A}}, \alpha(T)=\alpha_{0}\left(T_{0} / T\right)^{k_{\alpha}}
$$

with the following values of the coefficients:

\begin{tabular}{|c|c|c|c|c|c|}
\hline$E_{0}$ & $k_{E}$ & $A_{0}$ & $k_{A}$ & $\alpha_{0}$ & $k_{\alpha}$ \\
\hline $1199 \mathrm{MPa}$ & 0,24 & $115000 \mathrm{MPa}$ & 1,028 & 1,821 & 0,062 \\
\hline
\end{tabular}

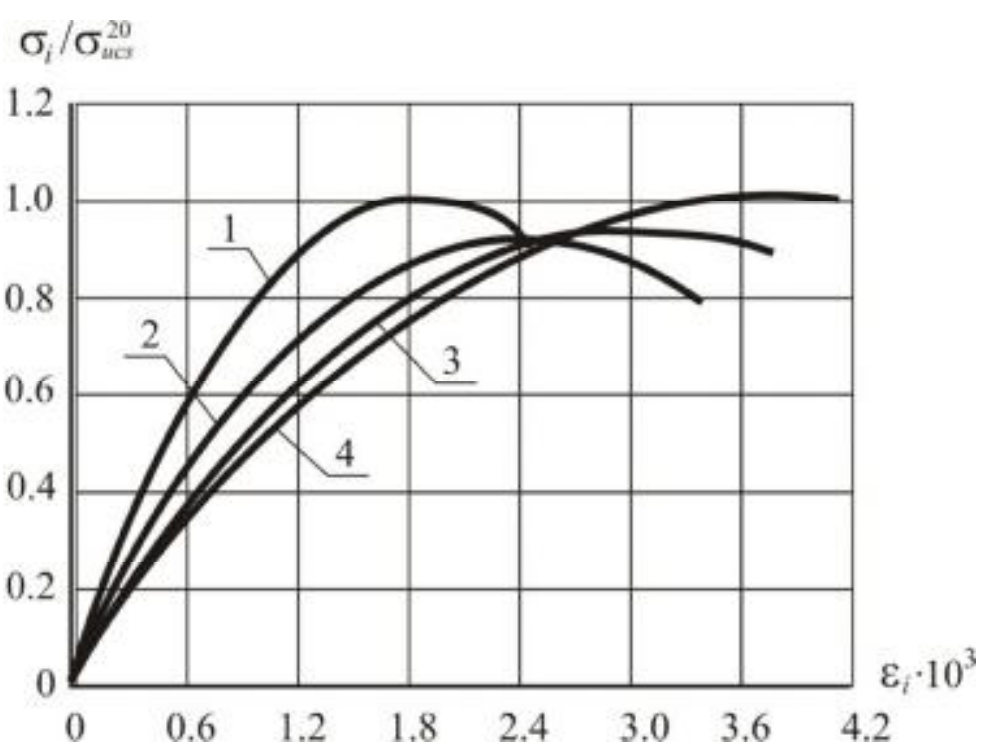

Fig. 5. Diagrams of concrete deformation in conditions of elevated temperatures,

$\sigma_{u c s}^{20}$ - ultimate compressive strength at $T_{0}=20^{\circ} \mathrm{C}$.

$$
\begin{gathered}
1-T=T_{0}=20^{\circ} \mathrm{C}, 2-T=60^{\circ} \mathrm{C}, 3-T=120^{\circ} \mathrm{C}, \\
4-T=200^{\circ} \mathrm{C} .
\end{gathered}
$$

Fig. 5 presents approximate diagrams of concrete deformation at elevated temperatures.

\section{Conclusions}

The obtained dependences of the characteristics of concrete on temperature can be used to calculate concrete and reinforced concrete structures. There is a large group of reinforced concrete engineering structures that are subjected to technological heating and the effect of outdoor temperatures. These include chimneys, silos for storage of hot products, tanks for oil and oil products, granulation towers and a number of other structures.Temperature effects for the group of engineering structures are practically always axisymmetrical.Constant and longterm loads are also practically axisymmetrical for almost all structures. This makes it possible to substantially simplify the solution of problems in determining the stress-strain state from the long-term action of temperature and loads for most structures.

To development of analytical and numerical methods for calculating thick-walled cylindrical and spherical shells from physically non-linear inhomogeneous material has been devoted several works by the authors $[8-10]$. 


\section{Acknowledgment}

This work was financially supported by the Ministry of Russian Education (state task $\# 7.1524 .2017 / \mathrm{PCh})$

\section{References}

[1]N.I. Karpenko, V.A.Eryshev, E.V.Latysheva, A.S.Bondarenko, Deformations of a reinforced concrete element with allowance for shrinkage deformations, Bulletin of the VolgGASU.(2013) 344-357.

[2]A.P.Krichevsky, Calculation of reinforced concrete engineering structures for temperature effects,Stroiizdat, Moscow, 1984.

[3] V.I. Andreev, Some problems and methods of mechanics of inhomogeneous bodies. Publishing House ASV, Moscow, 2002.

[4] N.I. Karpenko, General models of mechanics of reinforced concrete. Stroyizdat, Moscow, 1996.

[5] P.A. Lukash, Fundamentals of nonlinear construction mechanics, Stroyizdat, Moscow, 1978.

[6]V.I. Andreev, Yu.N. Malashkin, Calculation of a thick-walled tube from a nonlinear material, Construction mechanics and calculation of structures.6 (1983)70-72

[7]V.I. Andreev, L.S. Polyakova, Physically nonlinear problems for inhomogeneous thick-walled shells, International Journal for Computational Civil and Structural Engineering. 12 (2016) 36-40

[8] V.I. Andreev, L.S. Polyakova, Analytical solution of a physically nonlinear problem for an inhomogeneous thick-walled cylindrical shell, Vestnik MGSU. 11 (2015) 51-59

[9]V.I. Andreev, L.S. Polyakova, A.S. Avershyev, The solution of the nonlinear problems of elasticity theory for ground massif considering the inhomogeneity caused by soil moisture, Procedia engineering. 153 ( 2016 ) $45-50$

[10] V.I. Andreev, L.S. Polyakova,Numerical Methods for Solving Physically Nonlinear Problems for Inhomogeneous Thick-walled Shells, Applied Mechanics and Materials. 865 (2017) 325-330 